\title{
Osteonecrose e Síndrome da Imunodeficiência Adquirida
}

\section{Osteonecrosis and AIDS}

\author{
Brunela P. Borjaille(1), Letícia R. Brandão(1), Tatiana M. Hasegawa ${ }^{(2)}$, Renata F. Rosa ${ }^{(3)}$, \\ Silvio F. Antonio ${ }^{(4)}$,Wiliam H. Chahade ${ }^{(5)}$
}

\section{RESUMO}

A osteonecrose é uma terminologia que se refere à morte celular de dois componentes do osso: a medula hematopoiética e os osteócitos. É mais freqüente em homens do que em mulheres (8:1) e a maioria dos casos acontece em pacientes abaixo dos 50 anos de idade. Pacientes infectados pelo vírus HIV encontram-se em maior risco de desenvolver osteonecrose, estando implicados como fatores predisponentes a terapêutica antiviral, ao uso de corticosteróides e outros fatores associados, comuns à população geral. Os autores fazem uma revisão dos aspectos etiológicos, clínicos, patogênicos e diagnóstico, além de aspectos relacionados a esta entidade nos enfermos infectados pelo HIV.

Palavras-chave: osteonecrose, HIV, terapêutica anti-retroviral (HAART).

\section{INTRODUÇÃO}

A osteonecrose, também denominada necrose avascular ou necrose asséptica óssea, não é uma entidade clínica específica. É o processo final comum de um grande número de condições que acarretam uma diminuição do suprimento sanguíneo ao osso(1) ${ }^{(1)}$ Em até $40 \%$ dos casos, não existe um fator de risco identificável ${ }^{(2)}$. Múltiplas etiologias podem estar associadas, dividindo-se em traumáticas (fraturas ou deslocamentos) e não-traumáticas. Dentre estas, as mais comuns são o abuso de álcool, diabetes mellitus, pancreatopatias, hiperlipemia, gravidez, hemoglobinopatias, exposição à radioterapia, uso de altas doses ou uso prolongado de corticosteróides, esteatose hepática, hiperuricemia, transplante renal, lúpus eritematoso sistêmico e outras doenças do tecido conjuntivo, doença de Gaucher, neoplasias

\begin{abstract}
Osteonecrosis is a generic term that refers to cell death in the two components of the bone: hematopoietic fat marrow and osteocytes. It is more frequent in men than women (8:1), with the vast majority of the cases being reported in patients under age fifty. $H I V$-infected patients appears to be at major risk to the development of osteonecrosis, and the predisposing factors listed are the antiretroviral therapy, corticosteroids use and others risk factors that can be encountered on the general population. The authors get thorough a review of the etiology, clinical picture, pathogenesis, diagnosis, and the selected aspects of this entity in $H I V$-infected individuals.
\end{abstract}

Keywords: osteonecrosis, HIV, antiretroviral therapy (HAART).

e imunossupressão.

A osteonecrose foi relatada em associação com o vírus HIV a partir de 1990, mostrando uma incidência crescente neste grupo especial. Múltiplos sítios são envolvidos em mais de $75 \%$ dos casos. A cabeça do fêmur é o local preferencialmente acometido, sendo este geralmente bilateral. ${ }^{(3,4)}$

\section{EPIDEMIOLOGIA CLIINICA DA OSTEONECROSE EM PACIENTES INFECTADOS POR HIV}

Apesar de vários relatos de osteonecrose em pacientes infectados pelo HIV, a incidência real de casos sintomáticos não foi estabelecida. Três trabalhos recentes citam uma incidência anual variando de 0,08 a 1,33\% ${ }^{(5-7)}$. A incidência

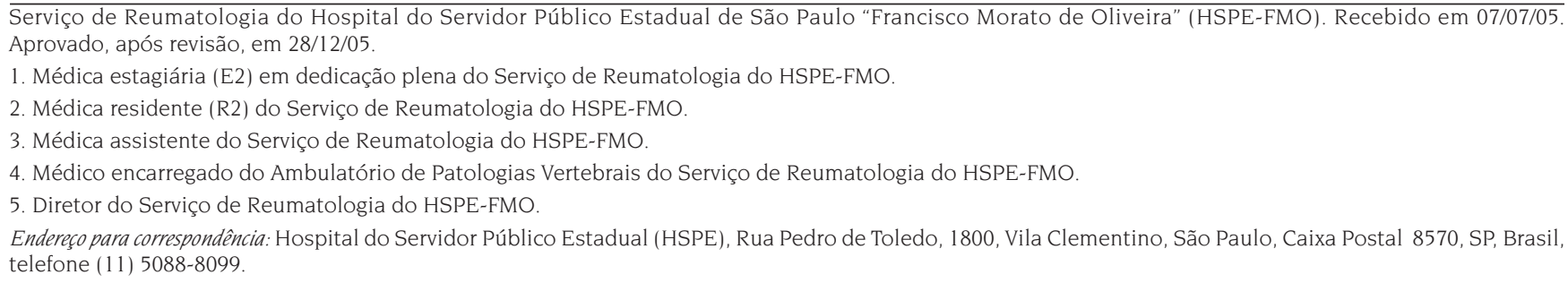


anual da osteonecrose na população geral é estimada entre 0,01 a $1,35 \%^{(6,8)}$. Um estudo utilizou a ressonância magnética para o diagnóstico de osteonecrose em 339 indivíduos assintomáticos com HIV, detectando uma incidência de $4 \%$ neste grupo $^{(9)}$.

Em vários relatos clínicos, a incidência de osteonecrose em pacientes infectados pelo HIV tem aumentado, às vezes de forma significativa, enquanto na população geral, permanece estável ${ }^{(5,6)}$. Em parte, este aumento pode refletir uma melhor condução destes pacientes em centros especializados, bem como a uma melhor precisão dos meios diagnósticos disponíveis. No entanto, devido à terapêutica anti-retroviral de alta potência utilizada na atualidade, torna-se possível que a mesma predisponha este grupo de pacientes ao desenvolvimento de osteonecrose ${ }^{(10)}$.

\section{ETIOLOGIA, ASSOCIAÇÕES E FATORES DE RISCO}

$\mathrm{Na}$ população geral, existe um alto grau de heterogeneidade entre as várias doenças conhecidas que levam ao desenvolvimento de osteonecrose. A via final comum para todas, no entanto, envolve morte do tecido ósseo causado por um comprometimento vascular. Tal fator se desenvolve em resposta à oclusão vascular (como nas doenças tromboembólicas), porém, pode também ocorrer seguindo-se aos danos físicos à parede vascular (como nas irradiações terapêuticas ou trauma). Assim, uma interrupção do suprimento sanguíneo resulta em isquemia, hiperemia reativa, um aumento na pressão intra-óssea e finalmente na morte do osteócito. A osteonecrose, geralmente, afeta o osso adjacente ao espaço articular, sendo esta área mais susceptível a comprometimentos vasculares. ${ }^{(11-13)}$

Em, aproximadamente, $60 \%$ das osteonecroses, na população geral, um ou mais fatores de risco podem ser identificados. Os $40 \%$ restantes são considerados idiopáticos ${ }^{(14)}$. Vários destes fatores de risco são encontrados rotineiramente entre pacientes com HIV, incluindo hiperlipidemia e utilização de corticosteróides, além de abuso na ingestão de álcool.

Apesar da patogênese da osteonecrose induzida por corticosteróides e pelo etanol ainda não estar completamente elucidada, tais agentes demonstraram capacidade de produzir alterações no metabolismo lipídico ${ }^{(15-17)}$. Estas alterações podem propiciar uma infiltração gordurosa na medula óssea, ocasionando obstruções ao fluxo sanguíneo para o osso e intra-ósseo ${ }^{(15,16)}$. Também pode ocorrer uma embolia gordurosa dentro da vascularização óssea. ${ }^{(16)}$

A utilização de acetato de megesterol como agente anticaquético em pacientes com HIV tem sido associada ao desenvolvimento de osteonecrose ${ }^{(6,18)}$.

Várias vasculites têm sido relatadas em associação com a infecção pelo HIV e tais processos inflamatórios têm sido implicados como causadores de alterações no endotélio vascular, resultando em obliterações insidiosas do lúmen endotelial e posterior bloqueio do fluxo sanguíneo ${ }^{(19,20)}$. Alguns investigadores têm sugerido as vasculites como responsáveis pelo desenvolvimento de osteonecrose em pacientes HIV positivos e pressupõem a participação dos anticorpos anticardiolipina como fatores etiológicos. Tal fato deve-se às seguintes associações: os anticorpos anticardiolipinas, em alguns estudos, estão presentes em 50 a $86 \%$ dos pacientes infectados pelo $\mathrm{HIV}^{(21-23)}$, um percentual bem maior do que o verificado na população geral. Estes anticorpos têm sido associados à osteonecrose em várias doenças auto-imunes ${ }^{(24)}$ e além do potencial para rompimento endotelial, estão associados a uma agregação plaquetária aumentada e aos fenômenos tromboembólicos ${ }^{(25)}$.

Outra condição que pode desempenhar um papel etiológico importante nesta infecção é uma deficiência adquirida da proteína $S$, que possui atividades antitrombóticas. A infecção pelo HIV tem sido associada tanto a essa deficiência adquirida, bem como ao desenvolvimento de anticorpos antiproteína $S^{(22,23)}$.

Manifestações reumatológicas são comuns na AIDS, como artralgias, artrites, espondiloartropatias seronegativas, poliomiosite e vasculites que ocorrem em até $72 \%$ dessa população. Osteonecrose é uma causa rara de dor articular comparada com outras doenças musculoesqueléticas, mas sua prevalência entre pacientes com AIDS não tratada e seu aparecimento em múltiplos sítios permite supor uma conexão entre diversos distúrbios imunológicos ou metabólicos causadas pela infecção pelo HIV e uma predisposição para osteonecrose.

A disponibilidade da terapia anti-retroviral de alta potência (HAART) tem sido implicada como fator de risco para osteonecrose, devido às alterações metabólicas bem reconhecidas destes fármacos. Em contraste, dois relatos de casos e um estudo controle concluíram que a HAART não é um fator de risco consistente para a osteonecrose em pacientes com HIV ${ }^{(26-29)}$. Devemos salientar que várias condições listadas na Tabela 1 têm sido relacionadas à HAART, ao HIV ou a ambos, incluindo hiperlipidemia, pancreatite, osteopenia, hiperuricemia e osteomielite.

A Tabela 1 sumariza os fatores etiológicos associados com a osteonecrose. 
TABELA 1

FATORES ETIOLÓGICOS ASSOCIADOS COM OSTEONECROSE 0steonecrose com etiologia conhecida

Traumática

Fratura da cabeça femoral

Luxação ou fratura de outras estruturas do quadril

Não-traumática

Anemia falciforme

Doença de Gaucher

Doença dos caixões (mergulhadores, descompressão)

Radioterapia

Osteonecrose com fatores etiológicos prováveis

Traumática

Trauma menor

Não-traumática

Arteriosclerose e outras doenças vasculares oclusivas

Intoxicação com tetracloreto de carbono

Uso de corticosteróides

Sindrome de Cushing

Diabetes mellitus

Alterações do metabolismo dos lípides

Displasias

Uso excessivo de álcool

Esteatose hepática

Hiperuricemia e gota

Osteomalácia

Pancreatite e doença de Weber-Christian

Gravidez

Transplante renal e colagenoses

Tromboflebite

Tumores

In: Mazieres B. Osteonecrosis. In: Hochberg MC, Silnan Aj et al. Rheumatology v.1v Philadelphia: Mosby; 2003, p.1886.

\section{QUADRO CLÍNICO}

Na população geral, a osteonecrose afeta primariamente os adultos jovens, entre 20 e 50 anos. Em geral, os pacientes têm menos de 40 anos na época do diagnóstico. Afeta predominantemente o sexo masculino na proporção de $8: 1^{(28)}$. A apresentação clínica é praticamente igual em pacientes com HIV e na população geral, com um predomínio discreto de múltiplos locais acometidos no primeiro grupo ${ }^{(1,2)}$.

A cabeça femoral é o local mais freqüente de osteone- crose, porém tal condição pode ocorrer em outros sítios, incluindo os côndilos femorais, a cabeça umeral, ossos do punho e dos pés.

A freqüência dos locais de desenvolvimento de osteonecrose, segundo as casuísticas da literatura, inclui o quadril (91\%), joelho $(87 \%)$, ombro $(72 \%)$ e tornozelo $(35 \%)$.

Os sintomas clínicos associados à osteonecrose da cabeça femoral são inespecíficos. O paciente pode ser totalmente assintomático em fases iniciais da doença. A dor pode se apresentar de maneira progressiva, geralmente com características mecânicas, por meses antes das alterações radiológicas estarem presentes. Em relação ao quadril, local mais freqüente de incidência desta condição, a dor pode localizar-se na região inguinal, na nádega, coxa e com irradiação para a face medial do joelho homolateral. A amplitude dos movimentos não está afetada nos casos iniciais, exceto quando a dor se mostra presente, quando o paciente pode apresentar bloqueio doloroso aos diversos movimentos do quadril, evoluindo posteriormente para limitação importante, após a ocorrência de alterações degenerativas tardias. Em relação ao uso de corticosteróides, em alguns estudos, a doença se mostrou clinicamente detectável em um período variável de dois meses a 10 anos, com a maioria dos casos tornando-se clinicamente aparente dentro de três anos após o início do uso destes fármacos ${ }^{(1,12,15,27)}$.

Recentemente em nosso Serviço assistimos um paciente com diagnóstico de AIDS há 11 anos, que foi tratado com várias drogas anti-retrovirais (AZT, ddl, indinavir, saquinavir, nelfinavir, 3TC.d4T, lamivudina, estavudina e efavirenz) além de corticosteróides em doses médias de $20 \mathrm{mg} /$ dia de

TABELA 2

Estágios da Osteonecrose - Diagnóstico por Imagem

\begin{tabular}{c|c|c}
\hline Estágio & Raio X Simples & RM/Cintilografia \\
\hline 0 & Normal & Normal \\
I & Normal & Anormal \\
II & $\begin{array}{c}\text { Osteopenia, esclerose óssea, cistos } \\
\text { subcondrais }\end{array}$ & Anormal \\
III & $\begin{array}{c}\text { Colapso subcondral ("sinal do } \\
\text { crescente”) sem achatamento da } \\
\text { superfície articular }\end{array}$ & Anormal \\
IV & $\begin{array}{c}\text { Achatamento da superfície articular } \\
\text { sem redução do espaço articular }\end{array}$ & Anormal \\
V & $\begin{array}{c}\text { Achatamento da superfície articular } \\
\text { com redução do espaço articular } \\
\text { e/ou envolvimento acetabular } \\
\text { Alterações degenerativas } \\
\text { avançadas }\end{array}$ & Anormal \\
VI & \begin{tabular}{c} 
Anormal \\
\hline
\end{tabular}
\end{tabular}

In: Mazieres B. Osteonecrosis. In: Hochberg MC, Silnan AJ et al. Rheumatology. v. 1. Philadelphia: Mosby; 2003. p.1883. 
prednisona, que evoluiu desde 2000 com múltiplos sítios de osteonecrose, iniciando-se em coxofemurais, joelho direito e posteriormente em ambos tornozelos.

\section{DIAGNÓSTICO DIFERENCIAL}

A dificuldade no diagnóstico diferencial da osteonecrose encontra-se nos estágios I e II. No estágio I, todas as doenças do quadril, que acometem respectivamente o osso, a cartilagem e os tecidos de sustentação devem ser consideradas. Na Tabela 2, mostramos os vários estágios da osteonecrose de acordo com as alterações nos métodos de imagem.

No estágio II, o diagnóstico diferencial mais difícil se faz com a osteoporose transitória do quadril, que pode estar presente nas algoneurodistrofias, onde pode ocorrer uma osteopenia da cabeça femural na radiografia simples. A ressonância magnética ( $\mathrm{RM})$, no entanto, mostra um alto sinal na algoneurodistrofia nas imagens ponderadas em T2, enquanto nos casos de osteonecrose uma intensidade de baixo sinal é característica. As fraturas subcondrais por estresse também se apresentam como um diagnóstico diferencial importante, sendo sua confirmação também auxiliada pela RM.

Nos estágios III e IV, a radiologia simples é mais sugestiva, com alterações características para o diagnóstico.

\section{DIAGNÓSTICO POR IMAGEM}

\section{RADIOLOGIA SIMPLES}

Nos estágios iniciais da doença, o raio X pode ser absolutamente normal. Com a evolução do processo, a alteração radiológica mais precoce é a osteopenia localizada. Após esta fase, inicia-se um processo de tentativa de restauração óssea, que pode conferir uma aparência mosqueada na área acometida, devido à presença de cistos ósseos subcondrais, que revelam áreas de reabsorção do osso necrótico, entremeadas com áreas de esclerose ${ }^{(30)}$ (Figura 1).
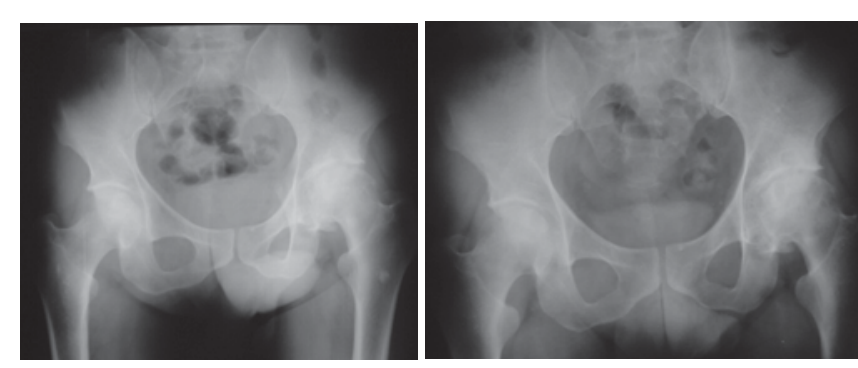

Figura 1 - Raio X com sinais de osteonecrose em articulação coxofemoral bilateral.
O colapso precoce do osso esponjoso, na região da placa subcondral, se mostra como uma linha radiolucente, patognomônica, descrita como "sinal do crescente" (Figura 2).

Apesar de uma relativa baixa sensibilidade, o raio X é a modalidade diagnóstica mais acessível de diagnóstico, sendo ainda considerado como o método de escolha ${ }^{(14)}$.

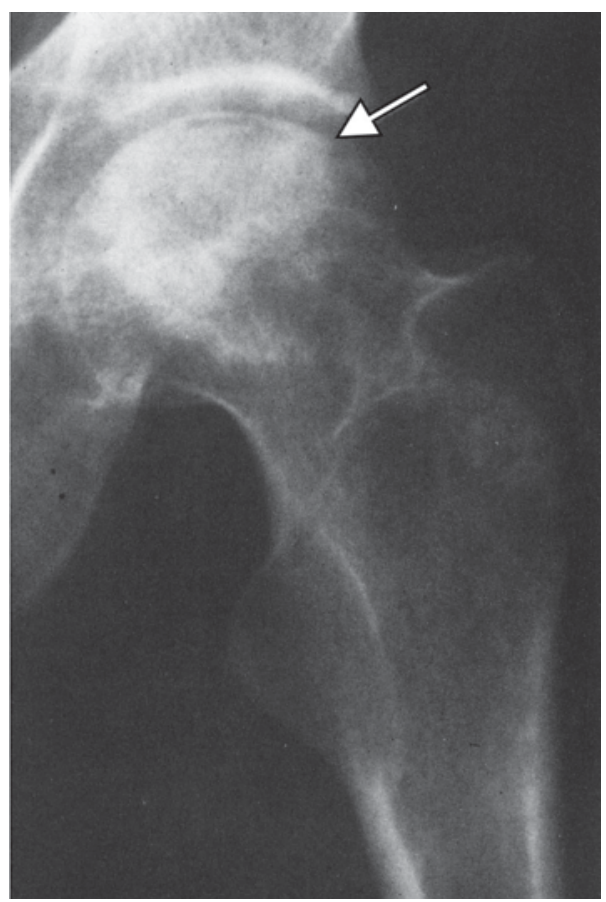

Figura 2 - Raio X mostrando o "sinal do crescente"(62).

\section{CINTILOGRAFIA ÓSSEA}

É um método capaz de detectar áreas de osteonecrose em um estágio mais precoce, em relação à radiologia simples, sendo, portanto, bastante sensível. No entanto, as áreas hipercaptantes nas regiões acometidas não são específicas e apresentam baixa resolução anatômica. A cintilografia óssea (CO) geralmente se mostra anormal, com aumento da captação na região da cabeça femural e outras áreas acometidas devido ao aumento de fluxo e um aumento no processo de remodelação associado com resposta reparadora à osteonecrose. Deve sempre ser interpretado em comparação com a articulação contralateral, podendo ter pouca utilidade em doença bilateral. É relativamente pouco sensível nos estágios pré-colapso, quando fornece resultados positivos em cerca de 70\% dos casos. Outros processos patológicos, com trauma ósseo recente, artropatias inflamatórias e tumores também se apresentam com um aumento na captação. Ocasionalmente, pode ser observada uma área fria (hipocaptante) dentro da região 
de hipercaptação (lesão "fria e quente"), sendo este achado bastante característico das osteonecroses ${ }^{(31)}$ (Figuras 3 e 4).

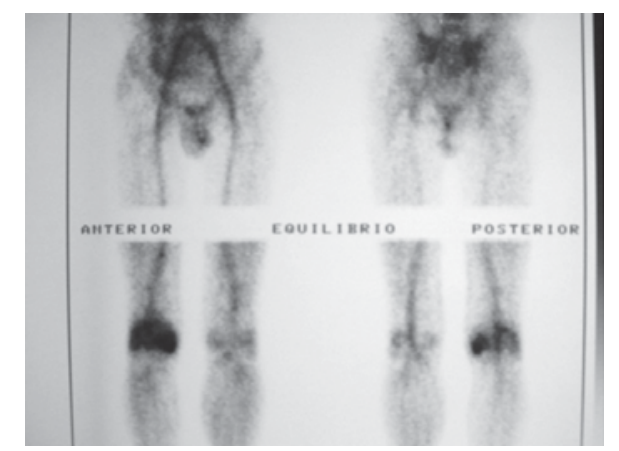

Figura 3 - Cintilografia óssea: reação osteogênica em articulação coxofemoral esquerda e joetho direito

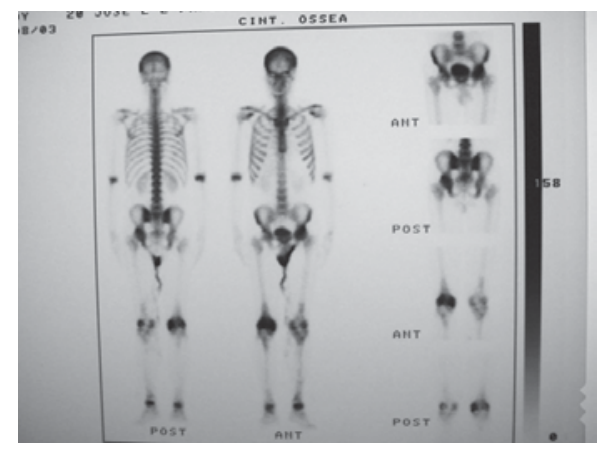

Figura 4 - Cintilografia óssea: hiperconcentração do traçado nas posições do joelho direito e tornozelos direito e esquerdo.

\section{RESSONÂNCIA MAGNÉTICA}

É um método de imagem muito mais sensível que a radiologia simples e a $\mathrm{CO}$, tornando-se nos dias atuais o exame de eleição para a confirmação diagnóstica das osteonecroses, mesmo nas fases mais iniciais da doença, onde os outros exames se mostram normais. Apresenta uma acurácia de cerca de $91 \%{ }^{(30)}$.

Nos estágios precoces, existe uma área de hipossinal no aspecto medial da cabeça femural, particularmente na região subcondral. Estes defeitos focais, envolvendo a região anterosuperior da cabeça femural, ocasionalmente estendendo-se até a metáfise, são as anormalidades mais comumente observadas, ocorrendo em $96 \%$ dos casos.

A imagem mais característica, observada em aproximadamente $80 \%$ dos casos, consiste de uma margem de baixa intensidade de sinal nas imagens ponderadas em $\mathrm{Tl}$ e $\mathrm{T} 2$. Uma margem interna de alto sinal associada com a referida anteriormente nas imagens em T2, chamadas de sinal da dupla linha, é considerada patognomônica para a osteone- crose e é descrita em 50 a 80\% dos casos. Esta imagem de alto sinal em T2 deve-se provavelmente a um aumento do conteúdo de água tanto no espaço intravascular e quanto no intersticial. Também pode ser devida à presença de tecido mesenquimal na medula subjacente ${ }^{(1)}$ (Figura 5).

Em estágios precoces, antecedendo o colapso, a RM tem uma alta sensibilidade e a melhor acurácia (75-100\%) quando comparada a outras técnicas de diagnóstico. No entanto, existem casos relatados de osteonecrose sem alterações significativas à RM.

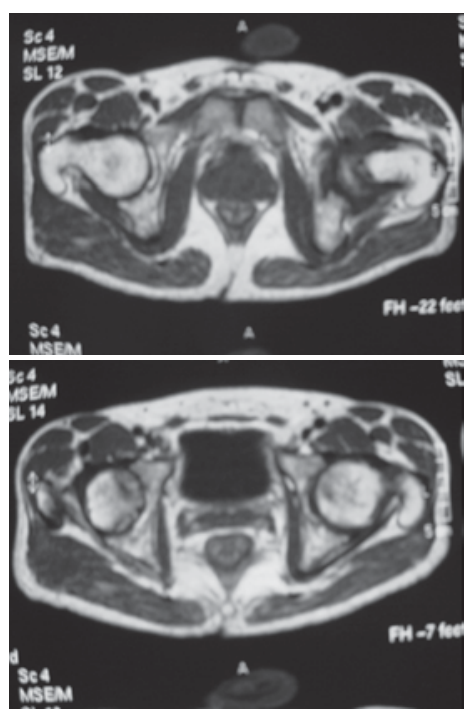

Figura 5 - RM de quadril: deformidades da epífise femoral esquerda, com baixo sinal em T1 e sinal heterogêneo em T2, também presente de forma menos expressiva à direita sofrendo tênue reforço.

\section{ANATOMIA PATOLÓGICA}

A osteonecrose envolve as células de dois tecidos ósseos distintos: osteócitos e células medulares. A necrose das células medulares é mais fácil de ser observada. $\mathrm{O}$ único sinal de necrose do tecido ósseo é a escassez dos osteócitos, cujas cavidades mostram-se vazias e freqüentemente aumentadas de tamanho, num percentual maior que $50 \%$ no tecido analisado ${ }^{(32)}$.

Em estágios avançados, como observados nas análises de cabeças femurais retiradas para prótese total do quadril, o seqüestro compõe-se de trabéculas mortas, sem a presença de osteócitos, porém com a arquitetura preservada, em geral, localizada abaixo da placa subcondral. Seu tamanho é variável, às vezes de pequenas dimensões e às vezes estendendo-se até a região metafisária. A fratura subcondral na origem da região do colapso está geralmente localizada no osso necrótico subcondral, em situação paralela com as margens da epífise, produzindo o aspecto radiológico clássico do "sinal do crescente" (33-35). 
A patologia da osteonecrose é bastante complexa, devido ao fato de alterações isquêmicas crônicas incompletas apresentarem-se simultaneamente as lesões reativas secundárias e alterações regenerativas, na dependência temporal e da área analisada. Arlet e Darroux propuseram um critério de classificação das alterações patológicas ${ }^{(36)}$ :

Tipo I. As lesões predominantes são claramente pré-necróticas e confinadas à medula óssea, apesar de ocasionalmente poderem ser observadas células espumosas e pequenas áreas de necrose reticular eosinofilica da medular óssea. A lesão mais comum é o edema intersticial ou plasmostasis.

Tipo II. O achado mais característico é o preenchimento completo dos espaços medulares com tecido necrótico, resultando em uma necrose reticular eosinofílica que se estende por vários centímetros nos espécimes de biópsia.

Tipo III. A necrose medular está associada com necrose trabecular, com cerca de 50 a 100\% das lacunas vazias.

Tipo IV. As lesões do tipo III estão presentes, porém, são encontrados também focos de fibrose medular, e as trabéculas necróticas estão presentes em número aumentado e envolvido por novas formações ósseas.

\section{PATOGÊNESE}

A interrupção mecânica da circulação da placa epifisária é comum à maioria das condições associadas à osteonecrose.

No caso de fraturas por deslocamento, ocorre uma interrupção abrupta do fluxo sanguíneo para a região afetada.

Nas doenças dos caixões ou dos mergulhadores, bem como na anemia falciforme, acontece um ingurgitamento da circulação sinusoidal por formações bolhosas compostas por nitrogênio, ou oclusão completa por hemácias falcizadas.

No entanto, os mecanismos de isquemia e/ou necrose ainda são discutíveis na maioria das causas não-traumáticas da osteonecrose. Algumas hipóteses são citadas:

\section{MICROFRATURAS E OSTEOPOROSE}

Frost $^{(37)}$ supôs que repetidas microfraturas poderiam induzir lesões microvasculares e posteriormente isquemia em ossos fragilizados, enquanto Laurent et al ${ }^{(38)}$ evidenciaram osteopenia em 20 e osteomalacia em 7 de 35 biópsias de crista ilíaca em pacientes com osteonecrose. Tais achados, entretanto, não foram reproduzidos em estudos posteriores, e a escassez de osteonecrose nas pacientes com osteoporose pós-menopausa fala contra esta hipótese.

\section{VASCULOPATIAS}

Estudos histopatológicos dos vasos de osteonecrose da cabeça femural mostram um aumento da formação de trombos de conteúdo lipídico, que condicionam um estreitamento do lúmen na microvascularização regional ${ }^{(39)}$.

\section{EMBOLIA GORDUROSA}

Jones propôs três origens prováveis para a embolia gordurosa: envolvendo esteatose hepática, desestabilização e coalescência de lipoproteínas plasmáticas e destruição da medula amarela ${ }^{(40)}$.

\section{HIPERTROFIA DAS CÉLULAS GORDUROSAS}

Os corticosteróides podem estar implicados na indução da hipertrofia dos adipócitos, que ocasionaria um aumento da pressão intramedular e redução do fluxo sanguíneo ósseo ${ }^{(41)}$.

\section{HISTÓRIA NATURAL E ASPECTOS EVOLUTIVOS}

Em pacientes com osteonecrose da cabeça femoral, o envolvimento silencioso e progressivo do quadril contralateral pode ocorrer em até $60 \%$ dos casos. Evidências sugerem que a taxa de progressão é alta, particularmente em pacientes sintomáticos. Estima-se que $68-80 \%$ das cabeças femorais com osteonecrose vão colapsar num período de até quatro anos após o diagnóstico inicial. Não existe relação nítida entre a etiologia causal e tempo de colapso ${ }^{(2,3)}$.

Nos estágios mais tardios, após colapso subcondral estabelecido e perda das características anatômicas e funcionais da articulação, a evolução para osteoartrose secundária é a regra, levando a procedimentos cirúrgicos em mais de $50 \%$ dos casos num período, em média, de três anos após o diagnóstico ${ }^{(42)}$.

Sinais de melhor prognóstico, com risco diminuído para o desenvolvimento de colapso são o envolvimento de menos de $25 \%$ do diâmetro da cabeça femoral, necrose acometendo menos de $1 / 3$ da área de carga articular e o acometimento de menos de $30 \%$ da área total da cabeça do fềmur ${ }^{(43)}$. Apenas 31 a $35 \%$ das osteonecroses em fase de pré-colapso tem um resultado clínico satisfatório sem procedimento cirúrgico ${ }^{(44)}$.

Em estudos clínicos prospectivos utilizando a CO e a RM como triagem em grupos de alto risco para osteonecrose, como, por exemplo, pacientes em uso crônico de corticosteróides, observou-se o diagnóstico em 15\% dos casos durante três anos de seguimento ${ }^{(45)}$.

\section{TRATAMENTO}

O tratamento baseia-se no estágio evolutivo da osteonecrose, de acordo com os critérios diagnósticos esta- 
belecidos, dividindo-se em conservador e cirúrgico.

O objetivo fundamental no tratamento é a prevenção do colapso ósseo e deformidades subseqüentes. Portanto, deve-se iniciar um tratamento precoce e bem conduzido enquanto a condição encontra-se nos seus estágios iniciais, em geral até o estágio II.

Devem-se utilizar mecanismos de descarga no quadril afetado, por um período não inferior a oito semanas, associados ao emprego de analgésicos de acordo com a necessidade dolorosa. As órteses são classicamente empregadas, porém mostram efetividade apenas nas osteonecroses com sinais de melhor prognóstico, conforme citados anteriormente.

Drogas vasoativas poderiam ter benefício nos casos iniciais de osteonecrose, apesar de difícil comprovação clínica em estudos controlados. Vasodilatadores periféricos como o oxalato de naftidrofuril, a diidroergotamina e a vincamina têm sido extensivamente usados no continente africano no tratamento das crises de falcização, pela sua ação, diminuindo a pressão intramedular ${ }^{(46)}$.

A utilização de campos eletromagnéticos ainda é uma forma de tratamento em investigação.

Várias técnicas cirúrgicas têm sido desenvolvidas na tentativa de prevenção da evolução para deformidades estabelecidas. A mais freqüentemente realizada é a descompressão medular da cabeça femoral, no intuito de diminuir a pressão intra-óssea e aumentar o fluxo sanguíneo regional. Vários estudos comparando esta modalidade cirúrgica com o tratamento conservador mostram resultados favoráveis, com taxas de sucesso de 47 a $84 \%$ nos estágios I a IV ${ }^{(31)}$.

O enxerto de tecido ósseo vascularizado da fíbula na cabeça femoral mostra-se extremamente promissor, com taxas de preservação da estrutura articular de até $89 \%$ em seguimento de 5 anos, quando realizados em doença estágio II a $\operatorname{IV}^{(47,48)}$.

O tratamento do grupo de pacientes com doença avançada, com colapso evidente, inclui a prótese total da articulação acometida, visando restabelecimento funcional da articulação e alívio do quadro doloroso. Alguns estudos têm sido realizados com a utilização de artroplastia superficial limitada do fêmur, porém, tal técnica ainda necessita de estudos por tempo mais prolongados e com um maior número de pacientes ${ }^{(49)}$.

\section{CONCLUSÃO}

Os esforços para um melhor entendimento da osteonecrose levam vários investigadores a caracterizar as relações entre fatores etiológicos e a sua patogênese ${ }^{(50)}$. Três grupos observaram que o início da osteonecrose após o tratamento com corticosteróides foi relativamente rápido, ocorrendo no período de um ano na maioria dos pacientes ${ }^{(51-53)}$. A possibilidade da relação do edema da medula óssea e osteonecrose foram estudadas por Fujioka et a ${ }^{53)}$ que não conseguiram caracterizar tal alteração em ressonâncias magnéticas realizadas em pacientes que desenvolveram osteonecrose após transplante renal e corticoterapia prolongada.

O desenvolvimento de um modelo animal que simule a doença humana é fundamental para um melhor conhecimento sobre a patologia e seu tratamento. Manggold et $a^{(54)}$, examinando a relação entre álcool e osteonecrose, demonstraram conseqüências limitadas em longo prazo da injeção direta de álcool na cabeça femoral. Em outro estudo, Irisa et $a^{(55)}$ utilizaram injeções de lipopolissacárides, reproduzindo vários achados da osteonecrose (patológicos, anormalidades da coagulação) e posteriormente avaliaram o tratamento farmacológico com varfarina. Porém, uma crítica a este modelo experimental baseia-se no fato das lesões osteonecróticas localizarem-se primariamente nas metáfises e diáfises e não nas cabeças femorais.

Nishii et al ${ }^{(56)}$ demonstraram que o colapso é dependente do tamanho da lesão. O tamanho da lesão também tem um efeito na taxa de sucesso em longo prazo de vários procedimentos cirúrgicos propostos no tratamento da osteonecrose. Todos relatos disponíveis de opções cirúrgicas demonstram uma melhor taxa de sucesso em estágios precoces da doença, anterior ao colapso da cabeça femoral ${ }^{(57-60)}$.

A osteonecrose nos pacientes portadores de HIV foi reconhecida mais recentemente, sendo os primeiros relatos a partir de 1990. Está bem definido que os pacientes portadores do vírus HIV constituem-se em grupo de risco aumentado para o desenvolvimento da osteonecrose. No entanto, estes pacientes também são mais propensos à exposição a outros fatores de risco associados à osteonecrose na população geral. Estima-se que até 15\% dos pacientes infectados pelo HIV desenvolvam osteonecrose ${ }^{(61)}$.

Tanto na população geral como nos indivíduos com HIV a osteonecrose é freqüentemente insidiosa. Devido à história clínica e os achados de exame físico serem inespecíficos, o médico assistente deve manter um alto índice de suspeita para esta comorbidade no grupo de pacientes infectados pelo HIV.

O raio X e a RM são os métodos de imagem de escolha na avaliação diagnóstica de todos pacientes suspeitos de osteonecrose.

A própria infecção pelo HIV e o tratamento anti- 
retroviral são considerados fatores de risco independentes. O uso de inibidores da protease pode ocasionar aumento dos níveis de triglicérides, que está implicada na patogênese da doença, além de associação com uma redução da densidade óssea. No estudo de Scribner et $a^{(6)}$, o saquinavir foi associado ao desenvolvimento de osteonecrose como fator de risco isolado. Outros fatores de risco comuns são o alcoolismo, a pancreatite, o uso de corticóide e os estados de hipercoagulabilidade. A presença de anticorpos anticardiolipina citada como fator de risco apresenta-se em mais de 50\% dos pacientes infectados. Geralmente, são do grupo IgM e não têm sido associado a eventos trom-

\section{REFERÊNCIAS}

1. Imboden J, Hellmann D, Stone JH: Current Rheumatology Diagnosis and Treatment, $\mathrm{I}^{\text {st }} \mathrm{ed}$, Philadelphia, 2004.

2. Chang CC, Greenspan A, Gershwin ME: Osteonecrosis: current perspectives on pathogenesis and treatment. Semin Arthritis Rheum 36: 23-47, 1993.

3. Solomon G: An approach to the human immunedeficience viruspositive patient. In R. Winchster. Philadelphia, WB Saunders Co. 17: 48-50, 1991.

4. Larrosa M, Cervantes M, Rossi P et al: Osteonecrosis in HIV infection patients: 21 affected joints in 9 patients. Arthritis Rheum 44(9): 124, 2001.

5. Keruly JC, Chaisson RE, Moore RD: Increased incidence of avascular necrosis of the hip in HIV-infected patients. J Acquir Immune Defic Synd 28: 101-2, 2001.

6. Scribner AN, Troia-Cancio PV, Cox BA, et al: Osteonecrosis in HIV: a case control study. J Acquir Immune Defic Synd 25: $19-25,2000$.

7. Timpone J, Fluhme D, Nascone J, Evans B, Kumar P: Avascular necrosis in HIV positive patients: a potencial link to protease inhibitors. Sixth Conference on Retroviruses and Opportunistic Infections. Chicago, January-February (abstract 680), 1999.

8. Brown P, Crane L: Avascular necrosis of bone in patients with HIV infection: report of six cases and review of the literature. Clin Infect Dis 32: 1221-6, 2001.

9. Miller KD, Masur H, Jones EC, Joe GO, Rick ME, Kelly GG et al: High prevalence of osteonecrosis of the femoral head in HIV-infected adults. Ann Intern Med 137: 17-25, 2002.

10. Allison GT, Bostrom MP, Glesby MJ: Osteonecrosis in HIV disease: epidemiology, etiologies, and clinical management. AIDS 17: 1-9, 2003.

11. Mankin HJ. Nontraumatic necrosis of bone (osteonecrosis): New Engl J Med 326: 1473-9, 1992.

12. Wolfe CJ, Taylor-Butler KL: Avascular necrosis: a case history and literature review. Arch Fam Med 9: 291-4, 2000.

13. Arlet J: Nontraumatic avascular necrosis of the femoral head: bóticos, porém são necessários mais estudos controlados nesta área para evidenciar a verdadeira participação destes anticorpos na osteonecrose. Em pacientes infectados pelo HIV que apresentem dores persistentes no quadril, joelhos, ombro, especialmente na ausência de trauma, devem ser prontamente submetidos a estudos de imagem visando o diagnóstico precoce de osteonecrose. Com o aumento significativo da sobrevida destes pacientes recebendo tratamento anti-retroviral (HAART), muitos estão propensos a desenvolver osteonecrose, salientando-se assim a importância do reconhecimento e minimização dos fatores de risco na condução destes enfermos. past, present and future. Clin Orthop 277: 12-21, 1992.

14. Steinberg ME: vascular necrosis: diagnosis, staging, and management. J Musculoskel Med 14: 13-25, 1997.

15. Cruess R:. Steroid-induced osteonecrosis: a review. Can J Surg 24: 567-71, 1981.

16. Gold EW, Cangemi PJ: Incidence and pathogenesis of alcoholinduced osteonecrosis of the femoral head. Clin Orthop 143: 222-6, 1979.

17. Boskey AL, Raggio CL, Bullogh PG, Kinnett JG: Change in the bone tissue lipids in person with steroid and alcohol-induced osteonecrosis. Clin Orthop 172: 289-95, 1983.

18. Mann M, Malozowski S, Bacsanyi L, Gilbert C: Aseptic necrosis in HIV seropositive patients: a possible role for megestrol acetate. AIDS Patient Care STD 14: 405-10, 2000.

19. Chetty R: Vasculitides associated with HIV infection. J Clin Pathol 54: 275-8, 2001.

20. Major NM, Tehranzadeh J: Musculoskeletal manifestations of AIDS. Radiol Clin North Am 35: 1167-89, 1997.

21. Canoso RT, Zon LI Groopman JE: Anticardiolipin antibodies associated with HTLV-III infection. Br J Haematol 65: 495-8, 1987.

22. Hassell KL, Kressin DC, Neumann A, Ellison R, Marlar RA: Correlation of antiphospholipds antibodies and protein $S$ deficiency with thrombosis in HIV-infected men. Blood Coag Fibrinolysis 5: 455-62, 1994.

23. Sorice M, Griggi T, Arcieri P, et al: Protein S and HIV infections: the role of anticardiolipin and anti-protein $S$ antibodies. Thromb Res 73: 165-175, 1994.

24. Belmonte MA, Garcia-Portales R, Domenech I, FernandezNebro A, Camps MT, DeRamon E: Avascular necrosis of bone in human immunodeficiency virus infection and antiphospholipid antibodies. J Rheumatol 20: 1425-8, 1993.

25. Hoffman M, Monroe DM, Roubey RA: Links between the immune and coagulation systems: how do "antiphospholipid antibodies" causes thrombosis? Immunol Res 22: 191-7, 2001. 
26. Calza L, Manfredi R, Mastroianni A, Chiodo F: Osteonecrosis and highly active antiretroviral therapy during HIV infection: Report of a series and literature review. Aids Patient Care STDS 15: 1385-9, 2001.

27. Glesby MJ, Hoover DR, Vaamonde CM: Osteonecrosis in patients infected with human immunodeficiency virus: a casecontrol study. J Infect Dis 184: 519-23, 2001.

28. Donohue JP: Osteonecrosis. www.update.com 9(3): 1-12, 2001.

29. Allen SH, Moore AL, Tyrer MJ, Holloway BJ, Johnson MA: Osteonecrosis of the knee in a patient receiving antiretroviral therapy. Internat J of STD \& AIDS 13: 792-4, 2002.

30. Lee MJ, Corrigan J, Stack JP, Ennis JT: A comparison of modern imaging modalities in osteonecrosis of the femoral head. Clin Radiol 42: 427-32, 1990.

31. Biswas TK, Biswas S: Avascular necrosis in rheumatology practice. APLAR J Rheum 7: 175-8, 2004.

32. Hochberg MC, Silman AJ, Smolen JS, Weinblatt ME, Weisman MH: Rheumathology. 3th ed. Philadelphia, Mosby, 2003.

33. Hauzer JP, Pasteels JL: Pathology of bone marrow distant from sequestrum in non traumatic aseptic necrosis of the femoral head. Bone Circ Bone Necr (21) 73-6, 1989.

34. Rutishauer E, Taillard W: L'isquemie articulaire en patologie humaine et expérimentale. Rev Chir Orthop 52: 197-202, 1966.

35. Solomon L: Bone marrow oedema syndrome. J Bone Jt Surg 75B: 175-6, 1993.

36. Ficat P, Arlet J: Compte rendu du $1^{\circ}$ symposium international sur la circulation osseuse. Paris. Editions INSERM. 293-302, 1973.

37. Frost HM: The etiodynamics of aseptic necrosis associated with hypercorticism. Mayo Clin Proc 44: 255-8, 1969.

38. Laurent J, Meunier P, Courpron P, Edouard C, Bernard J, Vignon G: Recherches sur la pathogénie des necroses aseptiques de la hanche. Nouv Presse Méd 2: 1755-7, 1973.

39. Cheras PA, Freemont AJ, Sikorki JM: Intraosseous thrombosis in ischemic necrosis of bone and osteoarthritis. Osteoarthritis Cartilage 1: 219-32, 1993.

40. Jones Jr. JP: Osteonecrosis. In McCarty DJ: Arthritis and allied conditions. 3th ed. Philadelphia. Lea \& Febiger, 1545, 1989.

41. Wang GJ, Sweet DE, Reger SI, Thompson RC: Fat-cell changes as a mechanism of avascular necrosis of the femoral head in cortisone treated rabbits. J Bone Jt Surg 59A: 729-35, 1977.

42. Kim YM, Rhyu KH, Lee SH, et al: Can osteonecrosis of the femoral head be recurrent? Clin Res Rel Res 406: 123-8, 2003.

43. Shimizu K, Moriya H, Akita T, Sakamoto M, Suguro T: Prediction of collapse with magnetic resonance imaging of avascular necrosis of the femoral head. J Bone Jt Surg 76A: 215-23, 1994.

44. Mont MA, Hungerford DS: Non-traumatic avascular necrosis of the femoral head. J Bone Jt Surg 77A: 459-74, 1995.

45. Halland AM, Klemp P, Botes D, Van Heerden BB, Loxton A, Scher AT: Avascular necrosis of the hip in systemic lupus erythematosus: the role of magnetic resonance imaging. $\mathrm{Br} \mathrm{J}$ Rheumatol 32: 972-6, 1993.
46. West SG ed: Rheumatology secrets, 2nd ed. Philadelphia. Hanley and Belfus Inc, 2002.

47. Judet H, Gilbert A: Long-term results of free vascularized fibular grafting for femoral head necrosis. Clin Orthop 386: 114-9, 2001 .

48. Soucacos PN, Beris AE, Malizos K, et al: Treatment of avascular necrosis of the femoral head with vascularized fibular transplant. Clin Orthop 386: 120-30, 2001.

49. Adili A, Trousdale R: Femoral head resurfacing for the treatment of osteonecrosis in the young patient. Clin Orthop 417: 93-101, 2003.

50. Jones LC, Hungerford DS: Overview of osteonecrosis of the hip and current treatment options. Curr Op Orthop 14: 12-6, 2003.

51. Koo KH, Kim R, Kim YS, et al: Risk period for developing osteonecrosis of the femoral head in patients on steroid treatment. Clin Rheumatol 21: 299-303, 2002.

52. Oinums K, Harada $Y$, Nawata $Y$, et al: Osteonecrosis in patients with systemic lupus erythematous develops very early after starting high dose corticosteroid treatment. Ann Rheum Dis 60: 1145-8, 2001 .

53. Fujioka M, Kubo T, Nakamura F, et al: Initial changes of nontraumatic osteonecrosis of femoral head in fat suppression images: bone marrow edema was not found before the appearance of band patterns. Magn Reson Imaging 19: 985-91, 2001.

54. Manggold J, Sergi C, Becker K, Lukoschek M, Simank HG: A new animal model of femoral head necrosis induced by intraosseous injection of ethanol. Lab Anim 36: 173-80, 2002.

55. Irisa T, Yamamoto T, Miyanishi K, et al: Osteonecrosis induced by a single administration of low-dose lipopolysaccharide in rabbits. Bone 28: 641-648, 2001.

56. Nishii T, Sugano N, Ohzono K, Sakai T, Sato Y, Yoshikawa $\mathrm{H}$ : Significance of lesion size and location in the prediction of collapse of osteonecrosis of the femoral head: a new three dimensional quantification using magnetic resonance imaging. J Orthop Res 20: 130-6, 2002.

57. Steinberg ME, Larcom PG, Strafford B, et al: Core decompression with bone grafting for osteonecrosis of the femoral head. Clin Orthop 386: 71-8, 2001.

58. Aigner N, Schneider W, Eberl V, et al: Coree decompression in early stages of the femoral head osteonecrosis - an MRIcontrolled study. Int Orthop 26: 31-5, 2002.

59. Yoon TR, Song EK, Rowe SM, et al: Failure after core decompression in osteonecrosis of the femoral head. Int Orthop 24: 316-8, 2001.

60. Simank HG, Brocai DRC, Brill C et al: Comparison of results of core decompression and intertrochanteric osteotomy for nontraumatic osteonecrosis of the femoral head using cox regression and survivorship analysis. J Arthroplasty 16: 790-4, 2001.

61. Miller KD, Masur H, Jones EC et al: High prevalence of osteonecrosis of the femoral head in HIV-infected adults. Ann Inter Med 137: 17-25, 2002.

62. Resnick D, Niwayama G: Diagnosis of bone and joint disorders. 2th ed. WB Saunders, Philadelphia, 1988. 